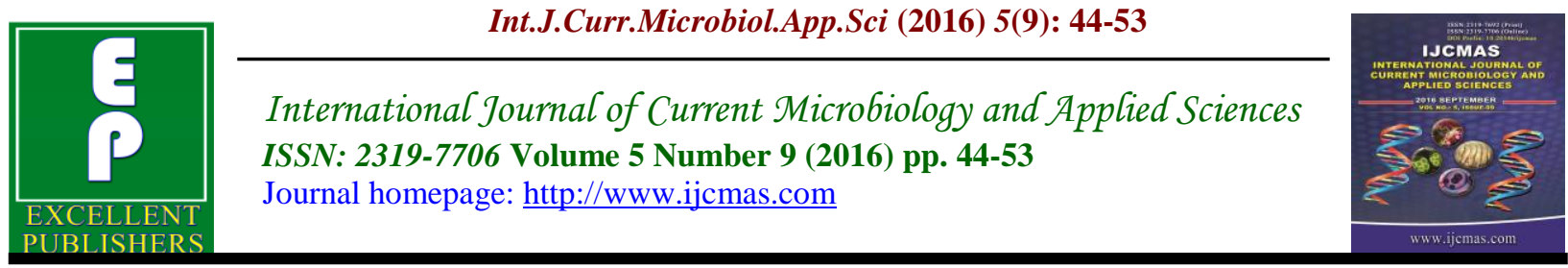

Original Research Article

http://dx.doi.org/10.20546/ijcmas.2016.509.006

\title{
Rapid Detection of Mutations in rpoB Gene of Rifampicin Resistant Mycobacterium tuberculosis Strains by Line Probe Assay in GGG Hospital, Jamnagar, Gujarat, India
}

\author{
Neela C. Katara*, Bindiya J. Ghedia and Mala Sinha \\ Department of Microbiology, Shree M. P. Shah Government Medical College \\ and GGG Hospital, Jamnagar, Gujarat, India \\ *Corresponding author
}

Keywords

Diagnosis of

rifampicin

resistance,

line probe

assay

\section{Article Info}

Accepted:

07 August 2016

Available Online:

10 September 2016

\section{A B S T R A C T}

Multidrug resistant (MDR) tuberculosis, resistance to at least rifampicin (RMP) and isoniazid (INH), is an increasing problem both in the developed as well as in the developing countries. The early diagnosis of tuberculosis and the rapid detection of resistance to the major anti-tubercular drugs is therefore, of utmost importance for the effective control of the resurgent epidemic. This study was carried out to detect rpo $B$ gene mutations in rifampicin resistant Mycobacterium tuberculosis isolated from MDR suspected sputum samples by line prob assay method. Total 3,346 MDR suspected (Criteria A,B,C) sputum samples were received in TB Culture -DST laboratory, Microbiology department, Guru Govind Singh Hospital, Jamnagar during study period for 6 months from January 2015 to may 2015 and proceeded for direct smear examination, DNA extraction, Amplification and Hybridization and detection of rpo $B$ gene mutations and rifampicin resistance by line probe assay method. Out of 3,346 samples, 2210 sputum samples were showing direct smear positive for acid fast bacilli suggestive of Mycobacterium tuberculosis. Out of 2210 direct smear positive samples, total 141 sputum samples were rifampicin resistant $M$.tuberculosis and studied for presence of rрo $B$ gene mutations by line probe assay method were most common wild type 8 were 77(54.6\%) absent and mutant type 3 were 104(74.0\%) present. The present study has shown detection of $r p o B$ gene mutations in rifampicin resistance M.tuberculosis is helpful to epidemiological purpose to prevent primary treatment failure,to study success rate and detection rate of various geographical area.

\section{Introduction}

Tuberculosis is a worldwide public health problem despite the highly effective drugs and vaccine is available making tuberculosis a preventable and curable disease (Joveria Qais Farooqi et al., 2012). Tuberculosis is the second-most common cause of death from infectious disease after those due to HIV/ AIDS (Dolin et al., 2010). 
A person with fully susceptible tuberculosis may develop secondary resistance during therapy because of inadequate treatment, not taking the prescribed regimen appropriately or using low-quality medications (O'Brien et al., 1994).

Drug-resistant tuberculosis is a serious public health issue in many developing countries, as its treatment is longer and requires more expensive drugs.

Conventional methods for mycobacteriological culture and drug susceptibility testing are slow and cumbersome, requiring sequential procedures for isolation of mycobacterium from clinical specimens, identification of Mycobacterium tuberculosis complex, and in vitro testing of strains susceptibility to anti-tuberculosis drugs. During this time patients may be inappropriately treated, drug resistant strains may continue to spread, and amplification of resistance may occur. Novel technologies for rapid detection of anti-tuberculosis drug resistance have therefore become a priority in tuberculosis research and development, and molecular line probe assays focused on rapid detection of rifampicin resistance are most advanced (Raviglione et al., 2006).

\section{Materials and Methods}

\section{Study duration \& sample size}

Total 3,346 MDR suspected (Criteria A,B,C) sputum samples were studied over a period of 5 months from January 2015 to May 2015 in the TB culture and DST laboratory, department of Microbiology, Guru Govind singh Hospital, Jamnagar

There were total 3,346 MDR suspected(criteria A,B,C) 2 sputum samples, one spot supervised and one early morning collected in sterile screw cap wide mouth falcon tube and transported from various centres received in TB Culture DST laboratory, Microbiology department, Guru Govind Singh Hospital, Jamnagar during study period.

The sputum samples were smeared for direct microscopy and following the gradings of smears, sputum samples were further proceeded for sputum decontamination, DNA extraction followed by Amplification and Hybridization and rpo $B$ gene mutations were detected in refampicin resistant Mycobacterial tuberculosis by line probe assay method.

\section{Inclusion and Exclusion criteria}

Detection of rpo $B$ gene mutation in refampicin resistant mycobacterium tuberculosis isolated from sputum samples by line prob assay method were included and other than sputum samples and sensitivity pattern of refampicin, isoniazid and mutation of isoniazid will be excluded.

\section{Ethical clearance}

It was a retrospective analysis of samples collected for routine diagnosis, so ethical consideration was not necessary.

\section{Results and Discussion}

Out of 3,346 samples, 2210 sputum samples were showing direct smear positive for acid fast bacilli suggestive of Mycobacterium tuberculosis were proceeded for line prob assay method following sputum decontamination and DNA extraction.

Out of 2210 direct smear positive samples, total 141 sputum samples were rifampicin resistant $M$.tuberculosis and studied for presence of rpo $B$ gene mutations by line probe assay method as shown in Table 1 . 
Table -2 shows sex wise distribution of rpo $B$ gene mutations in rifampicin resistant M.tuberculosis $95(67.00 \%)$ were from male patients and $47(33.0 \%)$ were from female patients.

Table -3 shows age wise distribution of rpo $B$ gene mutations in rifampicin resistant M.tuberculosis, 10-20 year were 06 (4.2\%), 21-30 year were 57(40.4\%) maximum resistant, 31-40 year were $37(26.0 \%), 41-50$ year were $24(17 \%)$, 51-60 year were $15(11.0 \%), 61-70$ year were $02(1.4 \%)$.

Table 4 shows direct smear positive grading wise distribution of rрo $B$ gene mutations in rifampicin resistant $M$. tuberculosis were $36(26.0 \%)$ grade $1,46(33 \%)$ were grade 2 , $40(28.0 \%)$ were grade +3 and $19(13.0 \%)$ were scanty.

Table- 5 shows rpo $B$ gene mutations in Rifampicin resistant M.tuberculosis with wild type 8 were $77(54.6 \%)$ absent and $64(45.4 \%)$ present, 3 were $18(12.8 \%)$ absent and $123(87.2 \%)$ present, 4 were $15(11.0 \%)$ absent and $126(89.0 \%)$ present, 7 were $10(7.0 \%)$ absent and 131(93\%) present, 5 were $03(2.0 \%)$ absent and 138(98\%) present,2 were 02(1.4\%) absent and $139(98.6 \%)$ present and 1 and 6 were $00(0 \%)$ absent and 141(100\%) present.

Table 7 shows rpoB gene mutation in Rifampicin resistant M.tuberculosis with mutant type absent and present were mutant type 3 were $104(74.0 \%)$ present and $37(26 \%)$ absent, mutant type 2-A were 08(6.0\%) present and 133(94.0\%) absent, mutant type 2 -A were $4(3.0 \%)$ present and $137(97 \%)$ absent, mutant type 1 were $9(6.4 \%)$ present and 132(93.6\%) absent.

In present study total direct smear positive pulmonary tuberculosis samples were 2210 out of 3,346 and proceeded for line probe assay.
Out of 2210 direct smear positive samples, total multidrug resistance tuberculosis were $332(9.92 \%)$. Out of it $141(4.21 \%)$ were rifampicin mono resistance compared with the study of Nilima Hirani et al showed that a total LPA was done on 2506 out of 4264 sputum samples, were 1420(33.3\%) MDR, $97(2.27 \%)$ were rifampicin mono resistance .In present study as compared to Nilima Hirani et al., total MDR were less and total rifampicin resistance were more as shown table 7 (Nilima Hirani et al., 2014).

In present study, showed that $r p o B$ gene mutation in rifampicin resistance caused by M.tuberculosis were more common in male $95(67 \%)$ as compared to female $46(33 \%)$, compared witth Neeraj raizada et al 230(72\%) male and 90(28\%) female, showed that $r p o B$ gene mutations in rifampicin resistant M.tuberculosis were more common in male as compared to female,that is similar to present study. The reason may be due to more outdoor activity of male as compared to female as shown in table 8 (Neeraj raizada et al., 2014).

In present study,the age-wise prevalence of rроB gene mutations in rifampicin resistant $M$. tuberculosis from sputum samples showed that aged group 21-30years 57 (40.4\%), while $31-40$ years $37(26.0 \%), 41-50$ years $24(17.0 \%)$ and 51-60 years 15 (11.0\%) ,compared with study of Shittu O Rasaki et al were age group 21-30 and 31 40 were more affected similar to present study as shown in table 9 (Shittu Rasaki et al., 2014).

In present study, the direct smear positive grading-wise prevalence of $r p o B$ gene mutation in rifampicin resistant $M$. tuberculosis were grade +2 showed $46(33 \%)$, while grade +3 were $40(28 \%)$, grade 1 were $36(26 \%)$, compared to study of Raj $\mathrm{N}$ yadav and Neeraj raizada were 
similar to study of Raj $n$ yadav. In study of Neeraj raizada study all grades were more compared to present study and most common was grade +1 as shown in table 10 (Raj yadav et al., and Neeraj raizada et al., 2014).

Table.1

\begin{tabular}{|l|l|l|l|l|}
\hline Total samples & Total Smear positive & Total LPA & Total MDR & $\begin{array}{l}\text { Rifampicin } \\
\text { resistance }\end{array}$ \\
\hline 3,346 & $2210(66.04 \%)$ & $2210(66.04 \%)$ & $332(9.92 \%)$ & $141(4.21 \%)$ \\
\hline
\end{tabular}

Table.2 Sex wise distribution

\begin{tabular}{|l|l|l|}
\hline Sex & Total No. & Percentage \\
\hline Male & 95 & $67.0 \%$ \\
\hline Female & 46 & $33.0 \%$ \\
\hline Total & 141 & $100 \%$ \\
\hline
\end{tabular}

Table.3 Age wise distribution

\begin{tabular}{|l|l|l|l|l|}
\hline \multirow{2}{*}{$\begin{array}{l}\text { Age } \\
(\text { years })\end{array}$} & \multicolumn{2}{|l|}{ Total No. } & \multirow{2}{*}{ Percentage } \\
\cline { 2 - 4 } & Male & Female & Total & \\
\hline $10-20$ & 2 & 04 & 06 & $4.2 \%$ \\
\hline $21-30$ & 34 & 23 & 57 & $40.4 \%$ \\
\hline $31-40$ & 28 & 09 & 37 & $26.0 \%$ \\
\hline $41-50$ & 16 & 08 & 24 & $17.0 \%$ \\
\hline $51-60$ & 13 & 02 & 15 & $11.0 \%$ \\
\hline $61-70$ & 02 & 00 & 02 & $1.4 \%$ \\
\hline Total & 95 & 46 & 141 & $100 \%$ \\
\hline
\end{tabular}

Table.4 Direct smear positive grading wise distribution of rpo B gene mutations in rifampicin resistant M. tuberculosis

\begin{tabular}{|l|l|l|}
\hline Direct smear grading & Total & Percentage \\
\hline+1 & 36 & $26.0 \%$ \\
\hline+2 & 46 & $33 . \%$ \\
\hline+3 & 40 & $28.0 \%$ \\
\hline Scanty & 19 & $13.0 \%$ \\
\hline Total & 141 & $100 \%$ \\
\hline
\end{tabular}


Table.5 rpoB gene mutations (Wild type) in Rifampicin resistant M.tuberculosis

\begin{tabular}{|l|l|l|l|l|}
\hline $\begin{array}{l}\text { Wild } \\
\text { type }\end{array}$ & $\begin{array}{l}\text { Total } \\
\text { (Absent) }\end{array}$ & $\begin{array}{l}\text { Percentage } \\
\text { (Absent) }\end{array}$ & $\begin{array}{l}\text { Total } \\
\text { (Present) }\end{array}$ & $\begin{array}{l}\text { Percentage } \\
\text { (Present) }\end{array}$ \\
\hline 1 & 00 & $0 \%$ & 141 & $100 \%$ \\
\hline 2 & 02 & $1.4 \%$ & 139 & $98.6 \%$ \\
\hline 3 & $\mathbf{1 8}$ & $\mathbf{1 2 . 8 \%}$ & 123 & $87.2 \%$ \\
\hline 4 & $\mathbf{1 5}$ & $\mathbf{1 1 . 0 \%}$ & 126 & $89.0 \%$ \\
\hline 5 & 03 & $2.0 \%$ & 138 & $98.0 \%$ \\
\hline 6 & 00 & $0 \%$ & 141 & $100 \%$ \\
\hline 7 & $\mathbf{1 0}$ & $\mathbf{7 . 0 \%}$ & 131 & $93.0 \%$ \\
\hline 8 & $\mathbf{7 7}$ & $\mathbf{5 4 . 6 \%}$ & $\mathbf{6 4}$ & $\mathbf{4 5 . 4 \%}$ \\
\hline
\end{tabular}

Table.6 rpo B gene mutation (Mutant type) in Rifampicin resistant M.tuberculosis

\begin{tabular}{|l|l|l|l|l|}
\hline Mutant & $\begin{array}{l}\text { Total } \\
\text { (Present) }\end{array}$ & Percentage & $\begin{array}{l}\text { Total } \\
\text { (Absent) }\end{array}$ & Percentage \\
\hline 1 & 09 & $6.4 \%$ & 132 & $93.6 \%$ \\
\hline $2-\mathrm{A}$ & 04 & $3.0 \%$ & 137 & $97.0 \%$ \\
\hline $2-\mathrm{B}$ & 08 & $6.0 \%$ & 133 & $94.0 \%$ \\
\hline $\mathbf{3}$ & $\mathbf{1 0 4}$ & $\mathbf{7 4 . 0 \%}$ & $\mathbf{3 7}$ & $\mathbf{2 6 . 0 \%}$ \\
\hline
\end{tabular}

Table.7 Comparition of total samples, total LPA done, total MDR, rifampicin resistance and isoniazide resistance

\begin{tabular}{|l|l|l|l|l|}
\hline Study & Total samples & Total LPA & Total MDR & $\begin{array}{l}\text { Rifampicin } \\
\text { resisntance }\end{array}$ \\
\hline Present study & 3346 & $2210(66.04 \%)$ & $332(9.92 \%) \%)$ & $141(4.21 \%)$ \\
\hline Nilima Hirani & 4264 & $2506(58.77 \%)$ & $1420(33.3 \%)$ & $97(2.27 \%)$ \\
\hline
\end{tabular}

Table.8 Comarition of Sex-wise distribution

\begin{tabular}{|l|l|l|}
\hline & Male & Female \\
\hline Present study & $95(67 \%)$ & $46(33 \%)$ \\
\hline Neeraj raizada & $230(72 \%)$ & $90(28 \%)$ \\
\hline
\end{tabular}

Table.9 Comparition of age-wise distribution

\begin{tabular}{|l|l|l|}
\hline $\begin{array}{l}\text { Age } \\
\text { range }\end{array}$ & Present study & $\begin{array}{l}\text { ShittuO } \\
\text { Rasaki }\end{array}$ \\
\hline $21-30$ & $57(40.4 \%)$ & $38(27.1 \%)$ \\
\hline $31-40$ & $37(26.0 \%)$ & $47(33.6 \%)$ \\
\hline $41-50$ & $24(17.0 \%)$ & $27(19.3 \%)$ \\
\hline $51-60$ & $15(11.0 \%)$ & $08(5.7 \%)$ \\
\hline
\end{tabular}


Table.10 Comparition of direct smear positive grading-wise prevalence of rpoB gene mutations

\begin{tabular}{|l|l|l|}
\hline Grade & Present study & $\begin{array}{l}\text { Neeraj } \\
\text { raizada }\end{array}$ \\
\hline+1 & $36(26 \%)$ & $110(34.0 \%)$ \\
\hline+2 & $46(33 \%)$ & $76(24.0 \%)$ \\
\hline+3 & $40(28 \%)$ & $98(31.0 \%)$ \\
\hline Scanty & $19(13 \%)$ & $36(11.0 \%)$ \\
\hline
\end{tabular}

Table.11 Comparition of absence of wild type band in rpoB gene mutation in rifampicin resistant $M$. tuberculosis With different studies

\begin{tabular}{|l|l|l|l|l|l|}
\hline Wild type & Present study & $\begin{array}{l}\text { Joveria Qais } \\
\text { Farooqi }\end{array}$ & Raj n yadav & $\begin{array}{l}\text { Neeraj } \\
\text { Raizada }\end{array}$ & P.kumar \\
\hline $\mathbf{8}$ & $\mathbf{7 7 ( 5 4 . 6 \% )}$ & $\mathbf{3 6 ( 6 7 . 9 \% )}$ & $2(40 \%)$ & $12(36 \%)$ & $\mathbf{6 2 ( 6 3 . 3 \% )}$ \\
\hline 3 & $18(12.8 \%)$ & $6(11.3 \%)$ & $5(100 \%)$ & $28(85 \%)$ & $2(2 \%)$ \\
\hline 4 & $15(11 \%)$ & $6(11.3 \%)$ & $5(100 \%)$ & $31(94 \%)$ & $3(3.1 \%)$ \\
\hline 7 & $10(7.0 \%)$ & $3(5.6 \%)$ & $4(80 \%)$ & $3(97 \%)$ & $2(2 \%)$ \\
\hline
\end{tabular}

Table.12 Comparition of presence of Mutant tyape band in rpoB gene mutations in rifampicin resistant $M$. tuberculosis with different studies

\begin{tabular}{|l|l|l|l|l|l|}
\hline $\begin{array}{l}\text { Mutant } \\
\text { Type }\end{array}$ & Present study & $\begin{array}{l}\text { Joveria Qais } \\
\text { Farooqi }\end{array}$ & Raj n yadav & Neeraj Raizada & P.kumar \\
\hline $\mathbf{3}$ & $\mathbf{1 0 4 ( 7 4 \% )}$ & $\mathbf{3 3 ( 6 2 . 3 \% )}$ & $\mathbf{2 ( 4 0 \% )}$ & $\mathbf{1 5}(\mathbf{4 6 \%})$ & $\mathbf{3 9}(\mathbf{3 9 . 8 \%})$ \\
\hline 1 & $9(6.4 \%)$ & $3(5.7 \%)$ & $00(0 \%)$ & $4(12 \%)$ & $2(2.0 \%)$ \\
\hline $2-\mathrm{B}$ & $8(6.0 \%)$ & $00(0 \%)$ & $00(0 \%)$ & $00(0 \%) \mathrm{S}$ & $1(1 \%)$ \\
\hline $2-\mathrm{A}$ & $4(3.0)$ & $2(3.8 \%)$ & $00(0 \%)$ & $2(6.0 \%)$ & $5(5.1 \%)$ \\
\hline
\end{tabular}

Fig.1

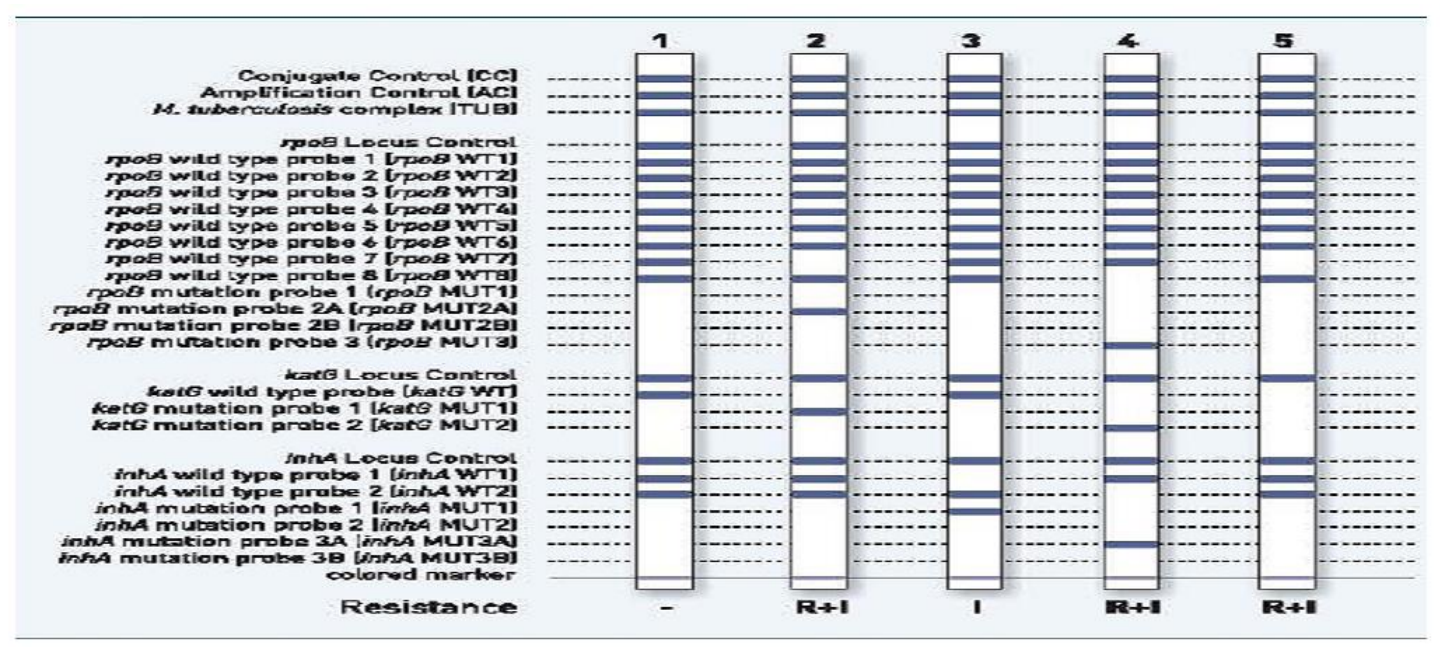




\section{Graph.1}

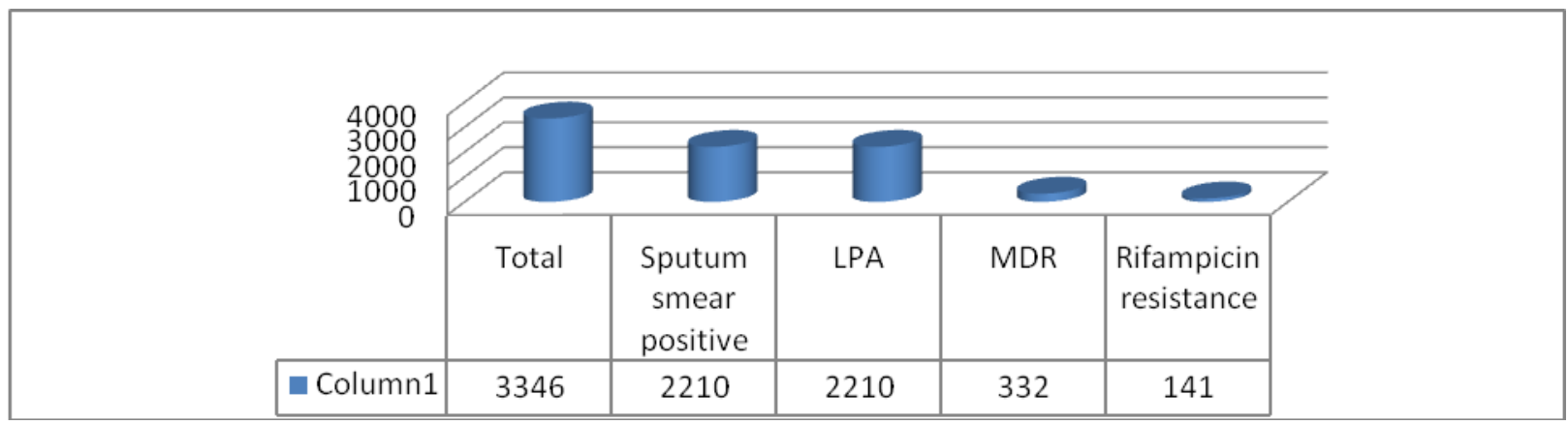

Graph.2 Sex-wise distribution

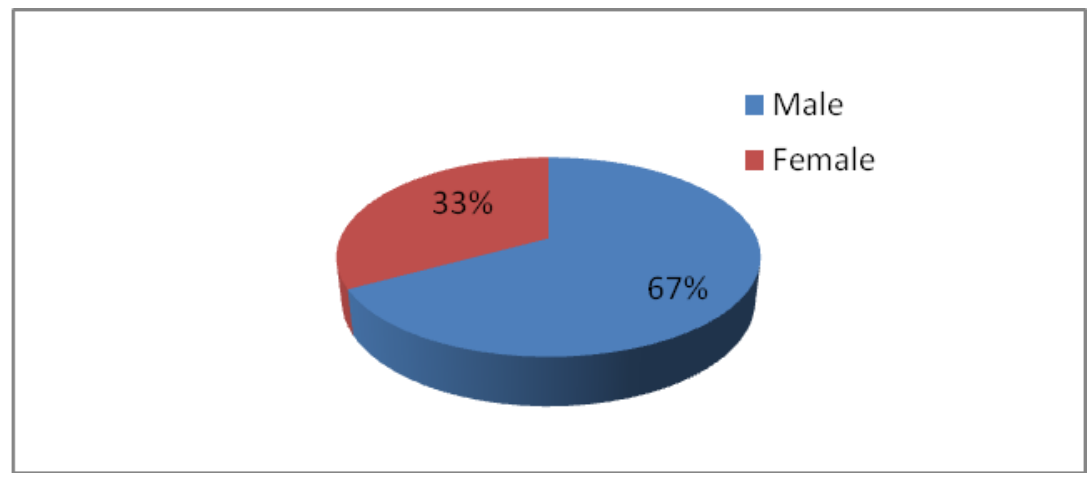

Graph.3 Age-wise distribution

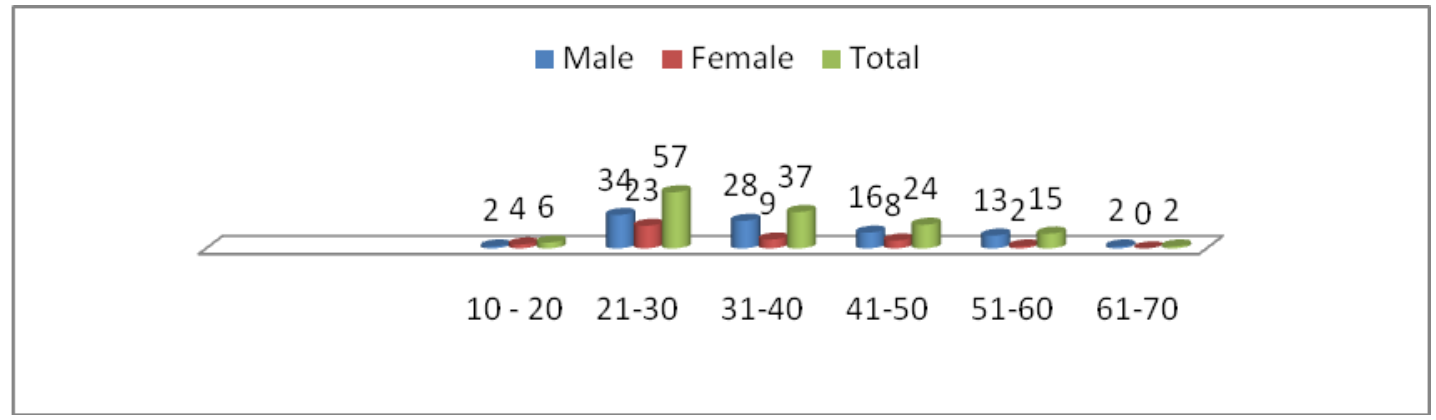

Graph.4 Direct smear positive grading-wise distribution

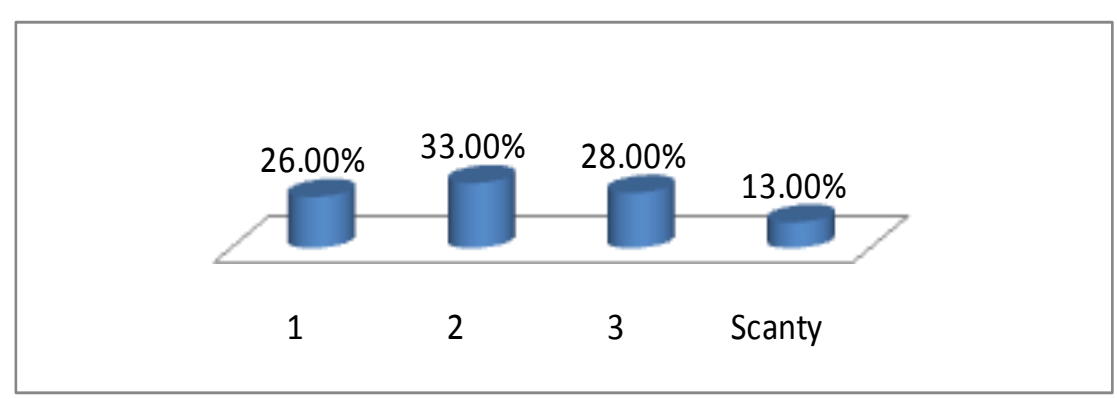


Graph.5 rpob gene mutation(wild type) in Rifampicin resistant M.tuberculosis

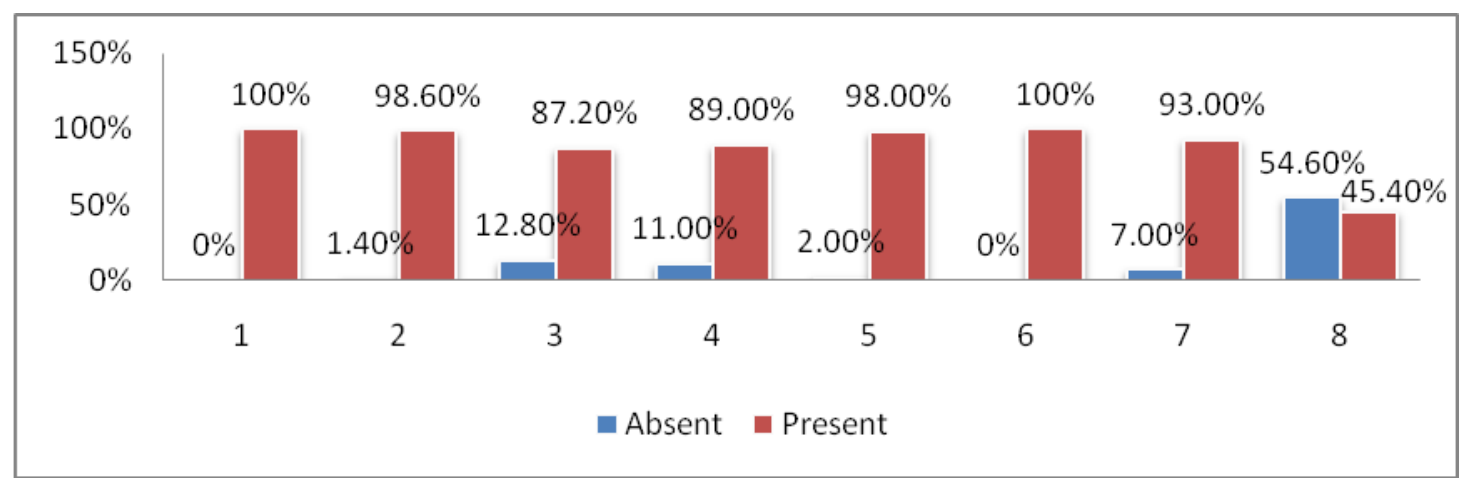

Graph.6 rpoB gene mutations (mutant type) in Rifampicin resistant M.tuberculosis

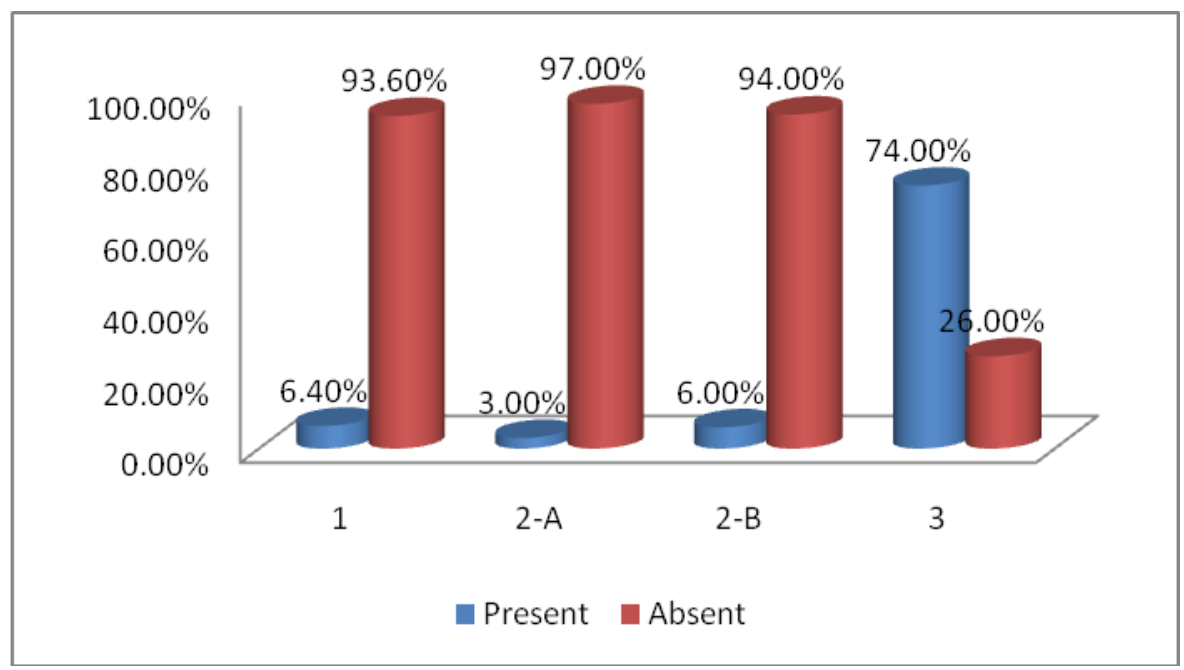

In present study, $r$ rpoB gene mutations in rifampicin resistant $M$. tuberculosis from sputum samples showed that most common wild type absent in rpo $B$ gene mutations, wild type 8 were $77(54.6 \%$ ) while wild type 3 were $18(12.8 \%)$, wild type 4 were $15(11 \%)$ and wild type 7 were $10(7.0 \%)$, were wild type 8 absent was most common compared to study of Joveria Qais Farooqi et al., 36(67.9\%), and kumar et al., $62(63.3 \%)$ were similar to present study. Were as in study of Raj n yadav 2(40\%) and in Neeraj Raizada study was $12(36 \%)$.The prevalence of wild type 8 was more in present study as compared to other studies as shown in table 11(Joveria Qais Farooqi et al., 2012; Raj yadav et al., 2013 and kumar et al., 2015).
In present study, $r p o B$ gene mutations in rifampicin resistant $M$. tuberculosis from sputum samples showed that most common mutant type present in rpo $B$ gene mutations, most common Mutant type 3 were $104(74 \%)$, while Mutant type 1 were 9(6.4\%), Mutant type 2-B 8(6.0\%) and mutant type 2-A 4(3\%), compared to study of Joveria Qais Farooqi 33(62.3\%), Raj n yadav 2(40\%), Neeraj Raizada 15(46\%) and P.nayak 39(39.8\%). The prevalence was more in presence study as compared to other studies. In comparison studies most common mutant type was mutant 3 ,similar to present studyas shown in table 12(Joveria Qais Farooqi et al.,2012; Raj yadav et al., 2013; Neeraj raizada et al., 2014; kumar et al., 2015). 
In conclusion, the presence study has shown detection of rрo $B$ gene mutations in rifampicin resistant M.tuberculosis is important factor to know patient's drug responce, treatment failure, relapse rate, reinfection of pulmonary tuberculosis. Early detection of rpo $B$ gene mutations in rifampicin resistance is helpful to start MDR TB treatment and to prevent XDR TB. Line probe assay can be helpful to detect $r p o B$ gene mutations and to detect which type of mutations are more common in rifampicin resistance. Study is also helpful to epidemiological purpose to prevent primary treatment failure. It is also useful to study the success rate and detection rate of various geographical area. Thus the INNO LiPA Rif TB proved to be a simple, rapid and reliable tool both for the identification of $M$. tuberculosis and for the characterization of the $r p o B$ gene mutations responsible for the resistance to rifampicin before the results of the conventional method are available. This assay has also been used to detect the presence of $M$. tuberculosis complex and its resistance to rifampicin directly from clinical samples and needs further evaluation. The LPA test provides an early diagnosis of mono resistance to isoniazid and rifampicin and is highly sensitive and specific for an early diagnosis of MDR-TB. Based on these findings, it is concluded that the LPA test can be useful in early diagnosis of drug resistant $\mathrm{TB}$ in high $\mathrm{TB}$ burden countries (Meera Sharma et al., 2013).

\section{References}

Dolin, Gerald, L., Mandell, John, E., Bennett, Raphael. 2010. Mandell, Dougl and Bennett's principles and practice of infectious diseases (7th ed.). Philadelphia, PA: Churchill Livingstone/Elsevier. pp. Chapter 250. ISBN 978-0-443-06839-3.116.

Joveria Qais Farooqi, Erum Khan, Syed
Muhammed Zaheer Alam, Asho Ali, Zahra Hasan, Rumina Hasan. 2012. Line probe assay for detection of rifampicin and isoniazid resistant tuberculosis in Pakistan, Department of Pathol. Microbiol., 1: 4-6; School of Nursing,2 Aga Khan University Hospital. Sales Agency Pakistan of Hain Lifescience, Gulistan-e-Jauhar, University Road, Karachi.3 Corresponding Author: Rumina Hasan.

Kumar, P., V. Balooni, S. 2015. Singh Genetic mutations associated with rifampicin and isoniazid resistance in MDR-TB patients in North-West India, Division of Clinical Microbiology and Molecular Medicine, Department of Laboratory Medicine, All India Institute of Medical Sciences, New Delhi, India Int. J. Tuberc. Lung Dis., 19(4): 434439.

Meera Sharma, Sunil Sethi, Baijayantimala Mishra, Caesar Sengupta \& S.K. Sharma. Department of Medical Microbiology, Postgraduate Institute of Medical Education \& Research, Chandigarh, India. Indian J. Med. Res., 117: pp 76-80.

Neeraj Raizada, K.S., Sachdeva, D.S., Chauhan, Bharti Malhotra, Kishore Reddy, P.V., Dave, Yamuna Mundade, Pranav Patel, Ranjani Ramachandran, Ram Das, Rajesh Solanki, Douglas Fraser Wares, Suvanand Sahu, Rick O'Brien, C.N., Paramasivan, Puneet, K., Dewan. A Multi-Site Validation in India of the Line Probe Assay for the Rapid Diagnosis of Multi-Drug Resistant Tuberculosis Directly from Sputum.

Nilima Hirani, Ameeta Joshi, Vaishali Wabale, Abhay Chowdhary. 2014. Detection and analysis of of Multidrug resistant TB(MDR-TB) 
cases by Molecular Line probe assay. Department of Microbiology, Grant government Medical college, Mumbai. Microcon-2014,Jaypur, Mycobacterilogy poster abstract, page:249.

O.'Brien, R. 1994. "Drug-resistant tuberculosis: etiology, management and prevention". Semin. Respir. Infect., 9(2): 104-12. PMID 7973169.

Raj, N., Yadav, Binit, K., Singh, Surendra, K., Sharma, Rohini Sharma, Manish Soneja, Vishnubhatla Sreenivas, Vithal, P., Myneedu, Mahmud Hanif, Ashok Kumar, Kuldeep, S., Sachdeva, Chinnambedu, N., Paramasivan, Balasangameshwra Vollepore, Rahul Thakur, Neeraj Raizada, Suresh, K., Arora, and
Sanjeev Sinha. 2013. Comparative Evaluation of GenoType MTBDRplus Line Probe Assay with Solid Culture Method in Early Diagnosis of Multidrug Resistant Tuberculosis (MDR-TB) at a Tertiary Care Centre in India.

Raviglione, M. 2006. XDR: Entering the post-antibiotic Era, 10: 1185-87.

Shittu, O., Rasaki, Akanbi, II A., AJibola, Sanni, A., Musa, Alabi, K., Moradeyo Odeigah, L.O., Sule, G., Abdullateef, Wale Adeoti, and Isiaka-Lawal, Salamat, Rasaki, et al. 2014. Rifampicin Resistant Tuberculosis in a Secondary Health Institution in Nigeria, West Africa Infectious Diseases \& Therapy, J. Infect. Dis. Ther., 2: 3 .

\section{How to cite this article:}

Neela C. Katara, Bindiya J. Ghedia and Mala Sinha. 2016. Rapid Detection of Mutations in rpoB Gene of Rifampicin Resistant Mycobacterium tuberculosis Strains by Line Probe Assay in GGG Hospital, Jamnagar, Gujarat, India. Int.J.Curr.Microbiol.App.Sci. 5(9): 44-53.

doi: http://dx.doi.org/10.20546/ijcmas.2016.509.006 